\title{
Ecos e Ressonâncias de Memória Do Reconhecimento ou da Condenação de Vidas
}

\begin{abstract}
José Mauro de Oliveira Braz
Doutorando em Memória Social pelo Programa de Pós-Graduação em Memória Social e Pedagogo pela Universidade Federal do Estado do Rio de Janeiro. Pesquisador participante do projeto $A$ construção da Memória da Educação Prisional do Estado do Rio de Janeiro (bolsista DS Capes). Tem como áreas-foco de pesquisa a Educação em Prisões, Educação de Jovens e Adultos e Legislação Educacional. Atualmente é suplente da Comissão de Educação no Fórum Estadual de Educação. Possui experiência na organização de audiências públicas e eventos acadêmicos, bem como na construção de legislação da área educacional.

jmobraz@yahoo.com.br
\end{abstract}

\section{Fernanda Santos Curcio}

Graduação em Serviço Social pela Universidade Federal Fluminense (2013) e Mestrado em Memória Social pela Universidade Federal do Estado do Rio de Janeiro (2016). Doutoranda em Memória Social pela Universidade Federal do Estado do Rio de Janeiro. Atualmente é bolsista da Capes, atuando, principalmente, nos seguintes temas: Serviço Social, Prisão, Gênero e Memória Social.nanda_fsc@hotmail.com

\section{Francisco Ramos de Farias}

Bacharel e psicólogo (1978) e especialista em Psicologia Clínica pela Universidade Federal do Rio de Janeiro. Mestre em Psicologia (1983) e doutor em Psicologia (1987) pela Fundação Getúlio Vargas - RJ (1987). Bolsista de Produtividade em Pesquisa 2. Consultor Ad Hoc da Fundação de Amparo à Pesquisa do Estado do Rio de Janeiro (Faperj), professor associado da Universidade Federal do Estado do Rio de Janeiro (Departamento de Fundamentos da Educação e Programa de Pós-Graduação em Memória Social). Consultor do Conselho Nacional de Desenvolvimento Científico e Tecnológico (CNPq). Assessor Científico da Fundação de Amparo à Pesquisa do Estado de São Paulo (Fapesp). Secretário Geral da Aninter-SH desde 2015. Tem experiência na área de Psicologia, com ênfase em Intervenção Terapêutica, atuando, principalmente, nos seguintes temas: crime, desejo, memória social, criminalidade e perversão.frfarias@uol.com.br

\section{RESUMO}

Pretende-se, neste texto, problematizar a rede de interpretações e lembranças construídas acerca da pessoa criminosa e em que grau esta tessitura contribui, ou não, para a perpetuação da pena, mesmo em circunstâncias nas quais tenha sido efetivado o seu cumprimento em termos do tempo de condenação, sob custódia no sistema penitenciário. Com o crescimento constante da população carcerária no Brasil nas três últimas décadas, a questão penitenciária vem à tona nos mais diferentes cenários, desde rodas de conversa informais até em reuniões de família e debates públicos. Em todos estes meios sociais uma figura central emerge em pontos diferentes das discussões, ou seja, a pessoa que transgride leis e normas, tornando-se, de certa forma, a personagem central das práticas penais. Indaga-se: Quais as redes de memórias que ecoam para contribuir com o não reconhecimento do valor da vida destes sujeitos? Como romper com estas memórias?

Palavras-chave: Memória. Crime. Reconhecimento.

\section{ECHOES AND RESONANCES OF MEMORY: THE RECOGNITION OR CONVICTION OF LIVES}

\section{ABSTRACT}

It is intended to problematize the network of interpretations and memories built about the criminal person and to what degree this structure contributes, or not, to the perpetuation of the sentence even in circumstances in which it has been fulfilled, in terms of the time of condemnation, in custody in the penitentiary system. With the constant growth of the prison population in Brazil, in the last three decades, the penitentiary issue is evident in different scenarios, ranging from informal conversations to family gatherings and public debates. In all these social circles a central figure emerges at different points in the discussions, the figure of one who transgresses laws and norms, becoming, in some ways, the central character of criminal practices. It is questioned: what networks of memories that echo to contribute to the non-recognition of the value of the life of these subjects? How to break with these memories?

Keywords: Memory. Crime. Recognition.

1 Introdução. 2 Da Memória ao Eco. 3 A Memória e o Reconhecimento. 4 Do Eco à Ressonância. 5 Da Ressonância à Memória: notas (in)conclusivas. 6 Referências 


\section{Introdução}

Ao observar a História da humanidade pode-se constatar o seguinte fato: as pessoas que apresentam diferenças e que são inscritas, negativamente, no contexto das relações sociais, incomodando ou atrapalhando certas camadas da sociedade, são inevitavelmente controladas em regimes de reclusão, ou segregadas fisicamente. Diante do exposto, nos arriscamos a afirmar que a reclusão de certas pessoas sempre existiu; consequentemente sempre existiram espaços de reclusão, e estes tinham como objetivo afastar as pessoas consideradas inconvenientes pelos setores do poder local. Chamemos aqueles que são excluídos de segregados, posto que, de fato, é isto que ocorre: uma efetiva segregação, no sentido de separá-los do restante da sociedade. Ao lançarmos um olhar sob a história dos segregados, constata-se, na Idade Média, uma grande preocupação com a questão da exclusão, basicamente em razão do surgimento e da rápida disseminação da lepra. Espaços de reclusão foram rapidamente criados e tiveram como principal argumento para a sua criação a contenção da propagação deste mal. Tais espaços denominaram-se leprosários e foram construídos como medida profilática, visando a não propagação da doença pela manutenção obrigatória em um espaço supostamente destinado à cura (FOUCAULT, 1996).

Ao final da Idade Média a lepra, em virtude do isolamento e da ausência de programas de tratamento, praticamente desaparece do mundo ocidental, resultando no surgimento de uma série de estabelecimentos desprovidos de uso, pois, como em muitos leprosários a mortandade concorria para o total desaparecimento dos doentes, não havia quem mais colocar ali dentro. Ao lançar olhar sob tais estabelecimentos, observa-se que sua arquitetura prima para a segregação, com muros altos, grandes portões e janelas pequenas. Logo, o mais lógico seria dar continuidade à utilidade deste espaço pelo viés que a própria estrutura disponibiliza. Se estas estruturas antes tinham o propósito de segregar, poderiam ser mantidas para a mesma finalidade, mudando apenas a categoria daqueles que seriam segregados. Diante de tal cena, os hospitais gerais, antigos leprosários, passaram a ser locais de exclusão destinados às mais diversas pessoas consideradas inconvenientes ou desagradáveis, dentre as quais haviam: portadores de doenças venéreas, miseráveis (pobres), vagabundos, prostitutas, alcoólatras, loucos, etc. Essas pessoas que expressam "um modo de ser" ou um "comportamento" diferente, acabam por ser, geralmente, deixadas a esmo por suas famílias, sendo desaprovadas moralmente em razão das particularidades de vida e tendo como destino o confinamento no hospital geral (FOUCAULT, 1996).

O tratamento, ou seja, a cultura vigente dos estabelecimentos que isolavam socialmente as pessoas diferentes, sempre esteve norteado pelo enquadramento moral, primando pela correção de maus hábitos e de paixões excessivas. Tratando-se de calabouços, prisões, hospitais gerais, enfim, independente da nomenclatura, esses espaços eram utilizados pelo poder local para manter os indesejáveis afastados. No âmbito dessa reflexão, contudo, o recorte preconizado concerne, especificamente, aos espaços prisionais, espaços específicos para conter os transgressores de determinadas normas sociais, conhecidos como criminosos.

No decorrer da história do criminoso houve também diferentes construções acerca do crime. $\mathrm{O}$ ato criminoso, na Antiguidade, era caracterizado como algo que contrariava a vontade do rei, e aquele que cometesse tal ato era isolado e colocado à espera do suplício, para servir de exemplo aos demais; poderia servir não apenas como exemplo, mas também para 


\section{Humanos}

Democracia

transformar o caráter do criminoso pela punição. Cabe salientar que os rituais eram verdadeiros espetáculos encenados publicamente, contando com a presença de grandes plateias, que incluíam convidados, e compareceria também um grande número de pessoas interessadas em presenciar o sofrimento e a morte do criminoso (FOUCAULT, 2010).

Atualmente, o criminoso é considerado aquele que transgride uma norma social específica e que, por esse motivo, contribui para a desordem social. A mudança de compreensão acerca do crime concorreu para a criação de instituições diferentes, resultado de mecanismos de punição. As instituições prisionais criadas pelo homem variaram conforme o seu contexto histórico-social em diversos aspectos, como grandeza espacial, luminosidade, localização do espaço na cidade e ações do encarcerador para com o encarcerado; porém um aspecto é constante, independente de qualquer modificação que a instituição sofra: a punição do criminoso. Tal punição, ponto nevrálgico do funcionamento das instituições prisionais, pode ser aplicada das mais diferentes maneiras. A atividade laboral forçada era uma dessas formas e ainda hoje é utilizada por alguns países. $O$ trabalho foi escolhido para ser uma prática punitiva, pois, segundo Faucher (1838), "o trabalho é a providência dos povos modernos; serve-Ihes como moral que preenche o vazio das crenças e passa por ser o princípio de todo o bem" (apud FOUCAULT, 2010). Depreende-se dessa observação a influência do pensamento iluminista, que foi responsável pela constituição de grande parte das ações políticas da Modernidade relacionadas aos encarcerados. A motivação pela aplicação do tratamento e da imposição da atividade laborativa é produto direto da concepção acerca do ócio que, enquanto na Antiguidade era visto como dádiva e oportunidade de crescimento pessoal, após a Revolução Industrial passa a ser considerado algo extremamente depreciativo, pois se o trabalhador está ocioso não está produzindo, e, para a lógica do capital, sem produção não há mais-valia.

A passos lentos a humanidade caminha na direção do tratamento do criminoso por um viés mais humanitário. Assim, diminuíram os castigos de caráter físico e aumentaram as punições de caráter moral. No contexto da história das prisões, observa-se que até recentemente os criminosos eram presos à espera de um castigo, porém, com o advento da Modernidade, as prisões mudam a sua finalidade para se converterem em espaços de punição visando à correção, com intuito de, no futuro, após o cumprimento da pena, o criminoso retornar ao convívio social externo à instituição de reclusão. Fundamentadas em preceitos considerados científicos, as prisões modernas deixam de ter como princípio o castigo físico e passam a dar ênfase à privação de liberdade (AGUIRRE, 2009).

Ainda com relação à prisão moderna, sua função e o público-alvo para o qual foi pensada, deve-se ter em mente que aqueles que se encontram encarcerados foram condenados por um crime praticado ou a quem foi imputada a autoria. Em uma ou em outra situação trata-se de uma modalidade de violência, mais especificamente a subjetiva (ZIZEK, 2014); não um ato por si só, mas um ato de violência que está previsto em lei, uma violência que é percebida como uma alteração no status das coisas, como aquilo que se opõe à ordem, ao frequentemente encontrado e desejado por parte da sociedade.

Sobre este fato é importante esclarecer que as condutas tipificadas enquanto ilícitas, são construções sociais e históricas, sofrendo transformações de acordo com as mudanças e interesses sociais. Como esclarece Christie (2011, p. 20), 
O crime não existe. Existem somente atos, aos quais frequentemente são atribuídos diferentes significados em cenários sociais diferentes. Os atos e seus significados são os nossos dados. Nosso desafio é seguir o caminho dos atos pelo universo de significados. [...] O crime está em permanente oferta. Atos passíveis de criminalização são como recurso natural ilimitado. Pouco pode ser considerado crime - ou muito. Atos não são, eles se tornam; seus significados são criados no momento em que ocorrem. [...] O crime é, portanto, produto de processos culturais, sociais e mentais. Para todas as condutas, inclusive aquelas tidas como indesejáveis, há dúzias de alternativas possíveis para sua compreensão: perversidade, loucura, honra distorcida, ímpeto juvenil, heroísmo político - ou crime.

O desrespeito às leis permite que os sistemas de segurança atuem sobre o sujeito, prendendo-o e confinando-o ao espaço conhecido como prisão.

A prisão, como toda instituição, precisa se manter útil para que não chegue ao fim, como ocorreu com os hospitais gerais. A questão central desse espaço social é a legitimidade, e para que isso aconteça é necessária uma incessante reprodução das práticas sociais, que são transmitidas permanentemente aos sujeitos encarcerados neste lugar, sempre por intermédio de ações que se desenvolvem neste cenário, objetivando a repetição, que culminam por se constituir para seus atores como hábitos.

Nesse sentido, alude-se que qualquer instituição, longe de ser um fenômeno individual, é construída para e por atores sociais. Isso significa que a mesma surge como resposta a diferentes demandas e problemas da sociedade, e, nesta lógica, para que uma instituição se mantenha e se reproduza, ela necessita de uma memória convergente a ela que propague a sua existência.

O ato da instituição de reproduzir a si mesma, segundo Costa (1997), produz memórias, uma delas a memória institucional, que se mantém por intermédio de um eterno movimento do que é instituído e o que vem sendo transformado: o instituinte. Este jogo pode ser compreendido sob duas perspectivas: a de uma memória-hábito, que conserva e memoriza as condutas e comportamentos dos sujeitos sociais, e a de uma memória-arquivo, quando determinadas regras e informações devem ser constantemente recuperadas para a manutenção de certa ordem vigente. De acordo com Bergson (1990), o hábito é um tipo de memória, e, por se tratar de um dispositivo de que todos os seres humanos fazem uso, acaba por instaurar o que deve ser lembrado ou não. Berger e Luckmann (2006) compreendem que toda e qualquer atividade humana está sujeita ao hábito, sendo este reproduzido a partir das instituições. É importante evidenciar que é neste âmbito que nosso entendimento acerca das instituições se debruça. Assim, o hábito de repetição no âmbito carcerário é uma necessidade a ser apresentada cotidianamente para preservar a memória da instituição, bem como para agir sobre os instituídos na tentativa de transformá-los.

Para pensar a memória que é produzida no cárcere, deve-se, em primeiro lugar, romper com o silêncio e o esquecimento que são produzidos do lado de fora do ambiente carcerário (FACEIRA, 2015). Essa não é uma tarefa fácil, pois pode, por vezes, revelar dinâmicas que incomodam aqueles que passam a percebê-las de alguma forma, ou mesmo aqueles que querem escondê-las. Além disso, deve-se levar em consideração que a memória caracteriza o homem, apontando caminhos futuros que podem ser reconhecidos no passado e vivenciados no presente, sempre atravessados por processos de socialização (FARIAS, 2015). 
Posto isto, retomemos a abordagem de alguns conceitos, como a memória hábito de Bergson, aliada a alguns conceitos da Física, para entendermos melhor a rede de memórias que se constitui em torno desta figura que ainda hoje é emblemática e causa as mais diversas querelas nos mais diferentes meios sociais: a figura da pessoa criminosa. Longe de querermos esgotar a reflexão apresentada, pretendemos trazer novas dinâmicas e abordagens, vislumbrando o aprofundamento deste pensamento em momentos posteriores.

\section{Da Memória ao Eco}

Levando-se em consideração que o hábito é um tipo de memória, denominada para esta abordagem de memória-hábito, tem-se que ela é entendida como uma memória que replica o passado, repete-o, contudo não é reconhecida como passado. Este tipo de memória utiliza o acervo da ação passada para a ação presente, replicando-se de forma automática. Um exemplo que pode ser dado acerca deste tipo de memória é aquela que é produzida pela memorização, muito presente em lições de casa em que ocorre o "saber de cor" (BERGSON, 1990).

Ao debruçarmos nosso olhar sobre os fenômenos físicos, tem-se que um deles, em particular, chamou a atenção, principalmente quando relacionado com o tipo de memória suprarretratado. Trata-se do fenômeno do eco. Na física matemática, o eco pode ser entendido como a reflexão de ondas sonoras em determinado ambiente, ou seja, ondas sonoras que se propagam por um ambiente e encontram uma superfície que faz com que elas alterem sua trajetória, mantendo a sua energia e forma. Nesse sentido, traçamos um paralelo entre ambos os conceitos apresentados para perceber que as memórias hábitos acabam por funcionar como um eco de memória, na medida em que, conforme Bergson (1990) pontua, essa memória se replica sem necessariamente ser alterada.

Posto isto, é importante para a proposta deste trabalho trazer à tona uma memória presente no discurso de grande parte da nação brasileira, particularmente da população da cidade do Rio de Janeiro. Tal memória não precisa de esforço para ser percebida, basta que se levante a temática do criminoso em qualquer roda de conversa que ela emergirá. Trata-se especificamente da memória que diz: bandido bom é bandido morto; e suas similares.

Um outro exemplo que pode ser apresentado, apenas para aprofundar a ilustração da problemática da repetição, é o relativo à estigmatização ${ }^{1}$ dos loucos. Esta categoria é, até a atualidade, considerada por muitos como perigosa. Cabe questionar, contudo: Como se sabe que o louco é perigoso? Se, digamos, uma criança, com desenvolvimento mental e idade adequados para realizar leituras de situações e ações perigosas, tem contato com um louco pela primeira vez, e este não dá evidência de representar perigo, a experiência da criança indica que aquele sujeito não é perigoso. Se, no entanto, uma pessoa que goza de total confiança do infante adverte-o a respeito do perigo que ele, o louco, pode abrigar dentro de si, ela imediatamente o classificará como perigoso. Muito provavelmente a pessoa que advertiu a criança também nunca experienciou uma ação agressiva por parte de um louco, mas, da mesma forma, deve ter sido advertida sobre o potencial perigo que este sujeito abriga. Concretiza-se,

Estigma, segundo Goffman (1974), pode ser compreendido como um sinal corporal, e tem por objetivo atenuar algo extraordinário ou mau sobre o status moral de alguém. 
assim, a transmissão de uma experiência ou de uma memória, e este processo acaba por vir a se repetir tanto com todos aqueles que são comumente percebidos quanto com aqueles que "não servem para viver em sociedade".

É necessário tratarmos de alguns aspectos e darmos importância à consistência de tal discurso enquanto memória, ou seja, caminhar para o entendimento do por quê esta frase se apresentar na memória da sociedade. Determinados sujeitos não são diretamente reconhecíveis como sujeitos, e, além disso, há vidas que improvavelmente são reconhecidas como vidas.

É na trama social que o ser humano se constrói, produz, reproduzindo e criando memórias. Dependemos do mundo a nossa volta - este que nos invade repetidamente ao longo da nossa existência, que nos ajuda nas interpretações e representações, que acaba sendo um produto de um campo inteligível -, que provoca, engendra e enquadra nossas percepções sobre a realidade que nos apresenta. Vivemos num campo de interpretações sociais elaboradas, que nos faz compreender e perceber o mundo de forma seletiva, esmaecendo a sensibilidade a determinados fatos e práticas e acentuando reações afetivas a outros.

Alguns discursos que entoam as pessoas segregadas são genéricos, universais, estereotipados e a-históricos. O medo, o perigo constante e generalizado e a insegurança que marcam esta realidade, juntamente com a ideia do Estado como um instrumento ineficaz e corrupto, não caminha na possibilidade de eliminar o preconceito; busca, ao contrário, exterminar os sujeitos estereotipados. Assim, a dificuldade de reconhecimento, atrelada ao sentimento de intolerância, torna-se cada vez mais presente, sendo comum a exigência de um policiamento mais ostensivo, a redução da maioridade penal, trabalhos forçados na prisão, pena perpétua, pena de morte, tortura e extermínio. Os discursos vêm se mostrando tão violentos quanto a prática do crime que gerou a figura que se quer destruir.

\section{A Memória e o Reconhecimento}

Falar da pessoa criminosa implica falar de crime, e, em razão do nosso objeto de reflexão ser a realidade brasileira, deve-se trazer à tona os estudos de Thompson (1993) acerca da crise do sistema penitenciário brasileiro e de como este sistema acaba por encontrar um fim em si mesmo, que difere do propósito da "recuperação" da pessoa criminosa sem dar retorno positivo à sociedade. Contraditoriamente aos alertas, o Brasil é um dos países com a maior população carcerária no mundo, que vem efetivando uma política de aprisionamento em massa, ocasionando em prisões completamente superlotadas em todo o território.

Outro fato que deve ser também considerado é que, segundo o Relatório da Anistia Internacional de 2015, as forças policiais do Brasil são as que mais matam no mundo. $\mathrm{Na}$ maioria dos casos, são homicídios de pessoas já rendidas, que foram feridas ou alvejadas. 0 relatório esclarece ainda que os assassinatos cometidos por policiais têm um impacto desproporcional na juventude de homens negros. Um dado ainda mais alarmante é que, no ano de 2014 , aproximadamente $16 \%$ dos homicídios registrados no Brasil tinham como autor um policial. 


\section{Humanos e}

Democracia

Mesmo com tal política de encarceramento e práticas de extermínio executadas por policiais, é comum escutarmos, nos mais diversos campos de discussão, que vivemos no país da impunidade. Resta sabermos em que tipo de impunidade tais discursos estão fundamentados, pois se constata a ausência de algum grau de comoção em torno da pessoa criminosa, principalmente pelo fato de $57 \%$ da população brasileira concordar com o extermínio de criminosos (EXTRA, 2016). Tal fato permite inferir que existe um silêncio da população em relação à criminalidade e às condições do tratamento deste problema social. Acerca disto, é importante mencionar que,

[...] o silêncio da sociedade, que se cala quanto às condições sub-humanas dos presídios, é uma das formas da violência simbólica. Esse silêncio pode estar representando perigosos espelhamentos simbióticos que abalam a pessoa moral e ética que somos [...]. Nessa ótica, a prisão, na sociedade global, torna-se uma instituição simbólica e exemplar para revelar a dinâmica de uma violência poliforme. Sua complexidade reside na ambigüidade de ser e não ser a imagem da própria sociedade. É a imagem como mecanismo de dominação, que na prisão é transparente e perpassa toda a organização social com o objetivo de transformar a vida humana em força (im) produtiva. Em contrapartida, aparece no imaginário da sociedade como uma anti-imagem, como seu contrário, pois, pelo fato de ser separada, discriminada, permite, aos que se encontram fora de seus muros, a sensação de serem livres, honestos, limpos e vingados (GUINDANI, 2001, p. 49).

As normas, por meio da repetição, agem produtivamente para constituir - ou não - alguns sujeitos; estas normas devem ser memorizadas, uma vez que a sua manutenção não é possível se as mesmas atuassem somente uma vez. A sociedade, no entanto, está atravessada por normas diferentes daquelas apresentadas em instituições. Tais normas constituem memória, ou, melhor dizendo, memórias; estas nos ajudam a conceber a temporalidade de nossas vidas, ligadas a uma ação contínua das normas do passado e do presente. Desta forma, entendemos que "a produção normativa do sujeito é um processo de iterabilidade - a norma é repetida e, nesse sentido, está constantemente 'rompendo' com os contextos delimitados como as 'condições de produção'" (BUTLER, 2015, p. 237). Partindo desta ideia de iterabilidade, percebemos as normas da sociedade não mais como modos determinísticos, admitindo, assim, que o homem e seu corpo estão expostos aos outros, sendo vulneráveis por definição. Com isso, sua mera sobrevivência depende de condições e instituições sociais, o que significa que, para "ser", no sentido de "sobreviver", o corpo tem de contar com o que está fora dele. 0 corpo é exterior a si mesmo. Isso significa que ele se faz no mundo dos outros, temporal e espacialmente não controlável. Nele estão presentes diversos sentidos que não são nossos, em que "o modo como sou apreendido, e como sou mantido, depende, fundamentalmente das redes sociais e políticas em que esse corpo vive, de como sou considerado e tratado, de como essa consideração e esse tratamento possibilitam essa vida ou não tornam essa vida vivível" (BUTLER, 2015, p. 85).

Aqui conseguimos compreender que a memória é capaz de manipular um entendimento objetivo sobre a realidade. Partindo da afirmação de Gondar (2003, p. 32), de que a memória é um instrumento de poder, e que "todo poder político pretende controlar a memória, selecionando o que deve ser lembrado e o que deve ser esquecido", há uma criação processual que não restaura um passado, mas, sim, o reconstrói diante do ângulo do presente. Neste 
espaço, certas vidas serão consideradas dignas de proteção e subsistência, enquanto outras vivenciarão a precariedade de forma mais intensa. Estamos, aqui, diante da questão do reconhecimento.

Como nos esclarece Butler (2015), a potência epistemológica de apreender uma vida, decorre, em parte, de que tal vida seja constituída em convergência com as normas que a definem como uma vida ou parte da vida. As normas novamente ganham força, na medida em que, pelas suas repetições, levam à produção dos meios aos quais os sujeitos são reconhecidos.

Então, o poder de apreender aquilo ou não como vida advém de normas que facilitem o seu reconhecimento. Determinados sujeitos não são diretamente reconhecíveis como sujeitos, e, além disso, há vidas que improvavelmente são reconhecidas como vidas. Assim, podemos entender que, na verdade, a condição de ser reconhecido não é atributo dos seres humanos; "as normas da condição de ser reconhecido preparam o caminho para o reconhecimento, os esquemas de inteligibilidade condicionam e produzem essas normas" (BUTLER, 2015, p. 21).

A esse respeito, Butler (2015, p. 33) afirma que, não havendo o enlutamento, o que está vivo não é considerado vida, ou seja, "há uma vida que nunca será vivida, que não é preservada por nenhuma consideração, por nenhum testemunho, e que não será enlutada quando perdida". Isso significa que, no caso específico tratado neste trabalho, alguns criminosos não terão suas vidas reconhecidas por determinados grupos, e isso, além de intensificar a precariedade da vida, abafa o reconhecimento de memórias relativas as suas presenças no seio da sociedade. Vivemos numa realidade em que se busca banir e excluir tudo aquilo que, entendido como grotesco, sujo, hediondo e indecoroso, rompe com as normas sociais e que não se reconhece enquanto humano, eliminando diferenças contagiosas e, portanto, perigosas. Em última instância, exclui-se a multidão (HARDT; NEGRI, 2001), ou seja, elimina-se todas as diferenças, anulando tudo aquilo que não poderá ser reduzido à unidade. Os discursos de violência, tortura e extermínio vêm sendo reproduzidos como reflexão de um som estarrecedor, que esbarra nas superfícies, voltando-se para trás, refletindo-se incessantemente.

\section{Do Eco à Ressonância}

Se vimos que há uma trama de intenções por detrás da memória que tem a função de eco, questiona-se: Como romper com este eco?

É incontestável o fato de que tais normas não são deterministas. Afinal, não estamos vivendo em um uníssono social. É apropriado lembrar que a trama normativa é marcada por jogos de força, em que os sujeitos são, antes de tudo, objetos de poder (FOUCAULT, 2012). O reconhecimento - assentado na memória -, além de ser produto social, não é um fato congelado, mas vive num eterno movimento de instabilidade, em que a qualquer momento uma regra pode ser substituída, um ideal contestado, uma relação social transformada, novos espaços e modos de socialização criados. 


\section{Hitos \\ Humanos e}

Democracia

O "conceito de memória, produzido no presente, é uma maneira de pensar o passado em função do futuro que se almeja" (GONDAR; DODEBEI 2005, p. 17); por conseguinte, a memória é uma categoria ética e política que se manifesta em algo realizável e imaginável, que nos ajuda também na perspectiva de lutarmos na construção de reconhecimentos de vidas que já foram enquadradas como "perdíveis" e não passíveis de luto.

Voltemos o olhar novamente para a física. Qual o fenômeno físico responsável pela quebra de um eco? Este é, precisamente, o fenômeno conhecido por ressonância. Em linhas gerais, a ressonância pode ser entendida como um fenômeno que ocorre no encontro de duas ondas, no qual a segunda onda vai de encontro à primeira. Ao se encontrarem, ambas as ondas somam suas energias e produzem uma nova onda, que terá diferentes propriedades quando comparada com as suas geradoras. É, acertadamente, ao olhar para este fenômeno físico que se pode pensar um engendramento social na intenção de "romper" com o eco produzido e "criar" algo novo.

A memória, para Gondar e Dodebei (2005), é uma criação processual que não restaura um passado, mas, sim, o reconstrói diante do ângulo do presente. Ela é algo que surge a partir das relações sociais, sendo o tempo o seu componente inseparável, e este, não sendo visto como algo neutro que remeta à deterioração ou à evolução, mas, sim, devendo ser compreendido como uma eterna transformação do real. O tempo, para as autoras, é Devir, que não se volve necessariamente a algum ponto ou desfecho; ele é um puro processo de tornar-se mais do que a coisa tornada.

Por tal entendimento, a memória não se reduz à representação. Ela é um fenômeno vivo, complexo e pulsante, em que as representações são apenas os referentes cristalizados daquilo que se encontra numa incessante mobilidade. A memória é muito mais do que um aglomerado de representações; ela exprime um conjunto de fatores irrepresentáveis, como as formas de querer e sentir, mas também práticas de si e ações inovadoras.

Na ressonância, como um fenômeno que se apresenta diante de um sistema físico que recebe energia por meio de excitações, fazendo com que tal sistema comece a vibrar com amplitudes cada vez maiores, a superposição de ondas altera a energia do sistema, modificando sua amplitude. Na constituição da memória é possível vislumbrarmos um movimento similar. As imposições do que lembrar, querendo ou não, produzem estímulos como respostas às incitações. As ondas aqui propagadas se chocam com as ondas subjetivas (também construídas) que dão forma a novos modos de existência que se recriam permanentemente. Logo, a possibilidade de existência se compõe de forças inéditas.

O sujeito social, enquanto aglomerado de hábitos e lembranças que interfere no seu entendimento do mundo e nas suas relações, constitui-se dentro destas ondas, podendo estas serem mais ou menos intensas. A conjugação de tais forças promove o encorpamento de sua existência.

A memória, aqui, deixa de ser entendida como um espaço sem demonstrativos de ação, "que apenas recebe inscrições codificadas para torna-se uma superfície vibrátil, reagindo à inscrição dos movimentos" (GONDAR, 2003, p. 35). É claro que as formas e movimentos ressonantes nunca serão os mesmos, variando de acordo com os códigos de assujeitamento e reprodução presentes histórico-socialmente. 
A memória tem, durante seus conflitos, disputas e embates, mas é também neste espaço que se manifesta a criação. É neste contexto que é possível vislumbrar novas formas e processos de liberdade e reconhecimento que possam vir a romper com a ratificação da perpetuação de práticas desumanas e hostis para com aqueles que transgrediram as leis penais, porque a memória, que num primeiro momento se afirma como um instrumento de poder, mostra-se também uma arma que dá forma ao novo e que auxilia o sujeito no uso de seu talento mais invejável: o ato criativo de modificar-se. Essa modificação vai, inevitavelmente, agir sobre a rede de relações sociais, permitindo sua transformação.

\section{Da Ressonância à Memória: notas (in)conclusivas}

Sem a pretensão de eleger tal trabalho como responsável por oferecer conclusões para essas questões, propõe-se uma discussão sumária, a partir de uma digressão, que nos leva a um novo campo de possibilidade de investigação.

As verdades/memórias produzidas na sociedade são inerentes aos poderes que se exercem sobre os sujeitos. Por outro lado, não é possível se conceber um relacionamento sem verdades/memórias que dão forma ao universo de referência do sujeito. Partindo desta assertiva, entendemos que as normas, por meio da repetição, agem produtivamente para constituir - ou não - alguns sujeitos, não apenas no passado, mas, inevitavelmente, através do tempo.

Estas normas devem ser assimiladas, uma vez que a sua manutenção não é possível se as mesmas atuassem somente uma vez. A memória, ou melhor, as memórias, nos ajudam a conceber a temporalidade de nossa vida, ligadas a uma ação contínua das normas do passado e do presente. É nesse cenário que memórias podem surgir funcionando na trama social como um eco. Constata-se que algumas destas memórias podem ser prejudiciais para a própria trama social. Acerca disto, trouxemos à tona o bordão "bandido bom é bandido morto", amplamente aceito na sociedade brasileira, como um dos exemplos na medida em que a própria existência desta "vontade de ver o bandido morto" minimiza as chances de a pessoa criminosa retornar à sociedade com efetiva condição de viver com qualidade, livre do estigma e do preconceito.

Romper com isso implica criar uma ressonância, que será aquilo que romperá com o eco produzido. Por mais, no entanto, que se diga muito acerca dos conceitos, fica uma lacuna do âmbito prático a ser preenchida. Como gerar a ressonância?

Uma das possíveis respostas aqui apresentada é a de que a ressonância deverá ser gerada, obviamente, no âmbito do discurso, aliado à efetivação de políticas públicas eficazes direcionadas às pessoas criminosas. Este discurso "ressonador" pode ser construído dentro de escolas e universidades, na medida em que a violência, o ódio e a segregação de grupos, como o das pessoas criminosas, é, por vezes, produto de ações que foram tomadas com base em memórias. Estas, ao funcionarem como ecos, foram transmitidas de uma geração para a outra, e são essas memórias que devem ser elaboradas ocasionando uma "inflexão e direção ao sujeito, reforçando a sua autoconsciência e o seu eu" (ADORNO, 1995, p. 48), intencionando criar novas memórias e, consequentemente, novos discursos em torno de uma questão que é problemática para a humanidade: a realização do crime e o destino do ator deste crime após o cumprimento da pena. 


\section{Humanos e}

Direitos

Democracia

Deve-se, contudo, ressaltar que o ambiente educativo não é, jamais foi, e rogamos para que nunca seja, concebido como redentor da solução dos problemas sociais. A escola, a universidade e a educação são possíveis caminhos para a construção de modos de vida e comportamentos sociais que admitam a convivência respeitosa com aqueles que são diferentes, com aqueles que, de alguma maneira, são segregados e marginalizados. Dessa forma, tem-se que um modo para a aceitação e compreensão do diferente é a aproximação (teórica e prática) entre os sujeitos.

\section{Referências}

ADORNO, T. Educação e emancipação. Rio de Janeiro: Paz e Terra, 1995.

AGUIRRE, C. Cárcere e sociedade na América Latina, 1800-1940. In: MAIA, C. N. et al. (Org.). História das prisões no Brasil. Rio de Janeiro: Rocco, 2009. V. 1.

ANISTIA INTERNACIONAL. Use of force. Amsterdã: Amnesty International, 2015.

BERGER, P.; LUCKMANN, T. A construção social da realidade. Petrópolis: Vozes, 2006.

BERGSON, H. Matéria e memória. São Paulo: Martins Fontes, 1990.

BUTLER, J. Quadros de guerra. Rio de Janeiro: Civilização Brasileira, 2015.

CHRISTIE, N. Uma razoável quantidade de crime. Rio de Janeiro: Revan, 2011.

COSTA, I. Memória institucional: a construção conceitual numa abordagem teórico-metodológica. 1997. 161 p. Tese (Doutorado em Memória Social) - Universidade Federal do Rio de Janeiro, Rio de Janeiro, 1997.

EXTRA. Para 57\% dos brasileiros, "bandido bom é bandido morto", diz Datafolha. 2016. Disponível em: <http:// extra.globo.com/noticias/brasil/para-57-dos-brasileiros-bandido -bom-bandido-morto-diz-datafolha-20400484. html>. Acesso em: 5 out. 2016.

FACEIRA, L. S. O trabalho nas prisões. In: FACEIRA, L. S.; FARIAS, F. R. (Org.). Punição e prisão. Rio de Janeiro: Lumen Juris, 2015.

FARIAS, F. R. Homens à deriva. In: FACEIRA, L. S.; FARIAS, F. R. (Org.). Punição e prisão. Rio de Janeiro: Lumen Juris, 2015.

FOUCAULT, M. História da loucura. São Paulo: Perspectiva, 1996.

Vigiar e punir. Petrópolis: Vozes, 2010.

. Microfísica do poder. São Paulo: Graal, 2012.

GOFFMAN, E. Estigma. Rio de Janeiro: LTC, 1974.

GONDAR, J.; DODEBEI, V. (Org.). O que é memória social? Rio de Janeiro: Contra Capa, 2005.

GONDAR, J. Memória, poder e resistência. In: GONDAR, J.; BARRENECHEA, M. (Org.). Memória e espaço: trilhas do contemporâneo. Rio de Janeiro: 7 Letras, 2003.

GUINDANI, M. A violência simbólica e a prisão contemporânea. In: Civitas - Revista de Ciências Sociais, Porto Alegre: Pontifícia Universidade Católica do Rio Grande do Sul, v. 1, 2001.

NEGRI, A.; HARDT, M. Império. Rio de Janeiro: Record, 2001.

THOMPSON, A. A questão penitenciária. Rio de Janeiro: Forense, 1993.

ZIZEK, S. Violência. São Paulo: Boitempo, 2014. 